\title{
PRESENCE OF LOW MOLECULAR WEIGHT LIPOPROTEINS IN CORD SERUM DEMONSTRATED BY HIGH PERFORMANCE LIQUID CHROMATOGRAPHY (HPLC)
}

\author{
Masako Hattori ${ }^{1}$, Kinsuke Tsuda ${ }^{1}$, Yutaka Seino ${ }^{2}$, Chiaki Ban ${ }^{3}$ and Hiroo Imura ${ }^{1}$ \\ ${ }^{1}$ Second Division, Department of Medicine, ${ }^{2}$ Division of Metabolism and Clinical Nutrition and \\ ${ }^{3}$ Department of Obstetrics and Gynecology, Kyoto University School of Medicine, Sakyoku, Kyoto \\ 606, Japan
}

\begin{abstract}
Lipoproteins in cord serum were analyzed by high-performance liquid chromatography (HPLC). We demonstrate three peaks of serum cholesterol which correspond to LDL, HDL2 plus HDL3, and smaller lipoproteins. The smaller lipoproteins in the third fraction, which were confirmed by electron microscopy, were not detected in adult serum. Cord serum HDL cholesterol correlated significantly with ApoE, CII, and CIII, while the smaller lipoproteins had a significant correlation with Apo AII and CII, but had no correlation with Apo E levels. Characterization of cord serum lipoproteins gives added insight into the dynamic equilibrium of several complex processes involved in lipid metabolism.
\end{abstract}

Cord blood is unique in lipid metabolism because it is not influenced by food intake. In order to elucidate the characteristics of lipoproteins in neonates, we have examined the lipoprotein cholesterol and apoproteins in cord blood and have determined the relationship between them. We adopted high-performance liquid chromatography (HPLC) (8) to separate lipoproteins of cord serum because it requires less time for analysis and there is no need for pretreatment of samples, and also because it provides high resolution and good reproducibility compared to the sequential ultracentrifugal floatation method (6) or electrophoresis (12).

\section{MATERIALS AND METHODS}

Blood Samples

Cord venous blood samples were obtained from 41 normal neonates, 18 males and 23 females, who underwent spontaneous fullterm vaginal delivery. All cases were without complications of delivery or of maternal illness which might affect the lipoprotein levels $(5,10,14)$. As control, venous samples were obtained from 10 healthy adult volunteers. Serum was separated promptly and stored at $-20^{\circ} \mathrm{C}$ until assayed.

\section{Determination of Total Cholesterol and Apoprotein Concentrations}

Total cholesterol levels were determined enzymatically employing a Determina-TC" $555^{\prime \prime}$ kit (Kyowa Medix, Tokyo). Assays of Apo AI, AII, B, CII, CIII, and E were performed by the single radial immunodiffusion (SRID) method (16).

\section{Separation of Lipoproteins}

Lipoproteins were separated by HPLC. Samples of $20 \mu 1$ were applied onto columns (G5000PW plus G3000SW) (Toyo Soda, Tokyo) and eluted with $50 \mathrm{mM}$ Tris- $\mathrm{HCl}$ 


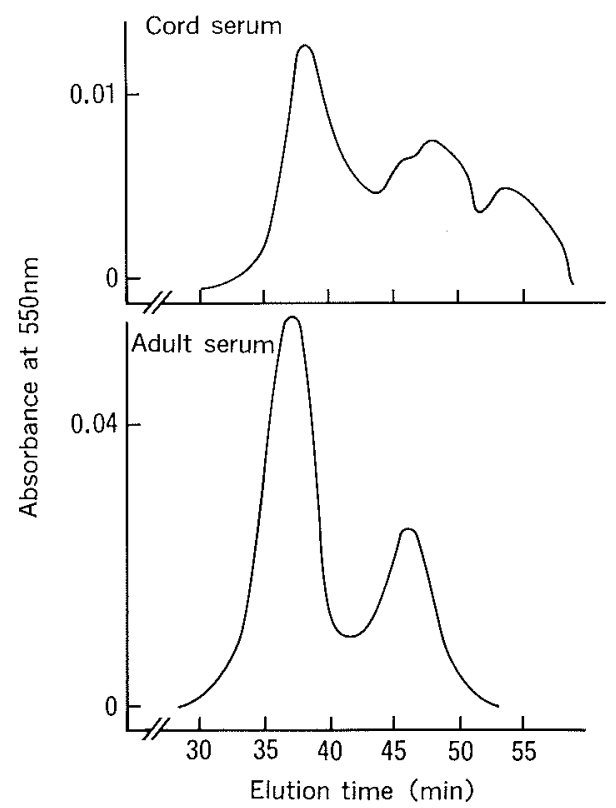

Fig. 1 Representative elution profiles of lipoprotein cholesterol in cord serum (upper) and adult serum (lower) in high performance liquid chromatography (HPLC). Cholesterol concentration was determined by enzymatic reaction and monitored at $550 \mathrm{~nm}$. The columns were calibrated with LDL and HDL standards.

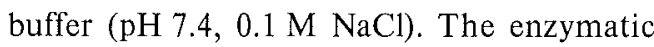
reaction was performed by passing the column effluent at a flow rate of $0.8 \mathrm{ml} / \mathrm{min}$ and the enzyme solution at a flow rate of $0.5 \mathrm{ml} / \mathrm{min}$ through a Teflon tube $(0.5 \mathrm{~mm} \times 20 \mathrm{~m})$ in a water bath at $50^{\circ} \mathrm{C}$. Cholesterol concentrations were monitored by the absorbance at $550 \mathrm{~nm}$. The columns were calibrated with LDL and HDL standards obtained from human plasma (Sigma Chemical, MO).

\section{Electron Microscopy}

The column effluents of three cases were collected, laid on a poly-L-lysine coated grid, negatively stained with $2 \%$ sodium phosphotungstate (2), and examined with a Hitachi $\mathrm{H}-500$ electron microscope.

\section{Statistical Analyses}

Statistical significance was evaluated by Student's $t$ test. The proportion of HDL in cord serum and adult serum was analyzed using Wilcoxon's rank sum test. Correlation coefficients were determined by linear regression analysis. The results were expressed as mean \pm SEM.

\section{RESULTS}

\section{Lipoprotein Cholesterol}

Fig. 1 shows the representative elution profiles of cholesterol in cord serum (upper) and adult serum (lower). Three peaks were observed in cord serum. The first and the second peaks corresponded to LDL (elution time: $37.2 \pm 0.2 \mathrm{~min}$ ) and HDL (elution time: $44.8 \pm 0.2 \mathrm{~min}$ ), as in adult serum (LDL: $37.0 \pm 0.6 \mathrm{~min}$, HDL: $44.9 \pm 0.7 \mathrm{~min})$. Separation of HDL2 and HDL3 was incomplete. The third peak (elution time: $54.2 \pm 0.5 \mathrm{~min}$ ) was observed in 32 of 41 cases in cord serum (78\%), and the low molecular weight lipoproteins were not detected in adult serum. We examined the effluent of the third peak by electron microscopy and confirmed the existence of small lipoprotein particles (Fig. 2).

Total cholesterol, LDL, HDL, and the small lipoprotein cholesterol concentrations in the cord serum are listed in Table 1. There was no difference between male and female neonates. Total cholesterol levels in cord serum were significantly lower $(P<0.01)$ than those in adult serum $(153.8 \pm 7.9 \mathrm{mg} / \mathrm{dl})$. No correlation was found between the total cholesterol level and the birth weight $(r=0.07)$. The proportion of HDL cholesterol to the total cholesterol was significantly higher $(P<0.05)$ in cord serum $(36.0 \pm 2.5 \%)$ than in adult serum $(19.6 \pm 1.3 \%)$.

\section{Apoproteins}

Whole serum apoprotein levels in the neonates and adults are shown in Table 2. No significant difference was observed between male and female neonates in each of the apoprotein levels. Apo E levels in cord serum were nearly the same as those in adult serum, while the other apoprotein levels in cord serum were significantly lower than in adult serum (Table 2).

Positive correlations were observed between HDL cholesterol levels and whole serum apoprotein $\mathrm{CII}(\mathrm{r}=0.58, P<0.01)$, CIII $(\mathrm{r}=0.54, P<0.01)$, and $\mathrm{E}(\mathrm{r}=0.52, P<0.01)$ 


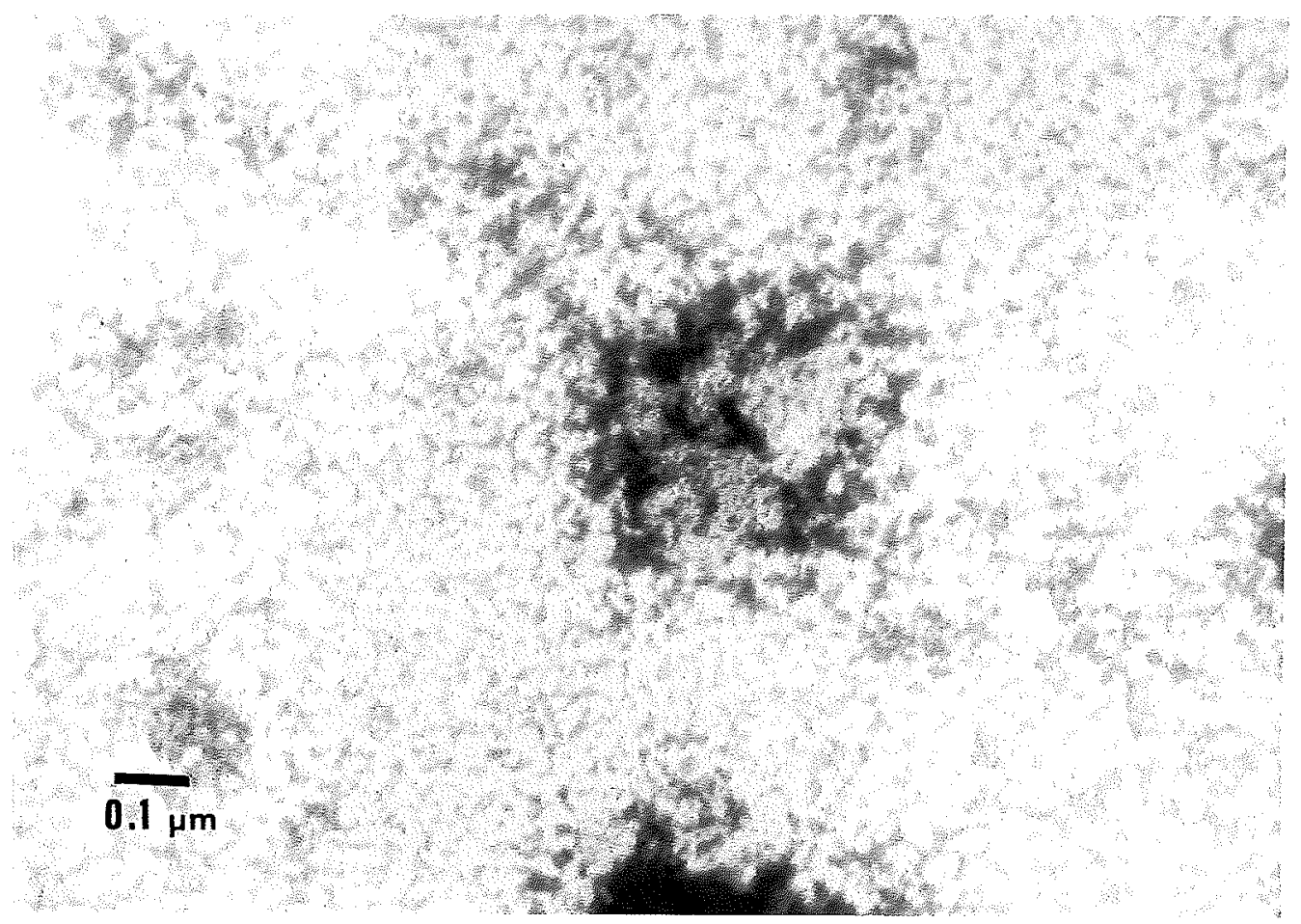

Fig. 2 Electron microscopy of lipoprotein particles eluted in the third fraction of cord serum. Hitachi $\mathrm{H}-$ 500 electron microscope was used after negative staining of the column effluent. The particle size was estimated to be less than $100 \AA$.

Table 1 Total Cholesterol and Lipoprotein Cholesterol Levels in Cord Serum

\begin{tabular}{lccc}
\hline & Male & Female & All subjects \\
\hline Total cholesterol & $61.3 \pm 2.9$ & $62.5 \pm 3.7$ & $62.0 \pm 3.4$ \\
Low density lipoprotein & $26.8 \pm 1.3$ & $27.9 \pm 1.9$ & $27.4 \pm 1.7$ \\
High density lipoprotein & $26.0 \pm 2.6$ & $28.5 \pm 3.2$ & $27.6 \pm 2.2$ \\
Small lipoprotein & $8.0 \pm 1.7$ & $5.8 \pm 0.9$ & $6.7 \pm 0.9$ \\
\hline
\end{tabular}

Values are expressed in $\mathrm{mg} / \mathrm{dl}$ of mean $\pm \mathrm{SEM}$.

Table 2 Apoprotein Levels in Cord Serum and Adult Serum

\begin{tabular}{lrrrr}
\hline & Male & $\begin{array}{c}\text { Cord serum } \\
\text { Female }\end{array}$ & All subjects & Adult serum \\
\hline Apo AI & $96.0 \pm 4.6$ & $96.0 \pm 3.3$ & $96.0 \pm 2.8$ & $126.6 \pm 3.7$ \\
Apo AII & $20.0 \pm 1.0$ & $21.0 \pm 0.6$ & $20.0 \pm 0.5$ & $27.5 \pm 1.2$ \\
Apo B & $33.0 \pm 2.4$ & $34.0 \pm 2.7$ & $34.0 \pm 1.9$ & $66.7 \pm 4.0$ \\
Apo CII & $1.8 \pm 0.2$ & $1.8 \pm 0.2$ & $1.8 \pm 0.1$ & $2.7 \pm 0.2$ \\
Apo CIII & $3.6 \pm 0.2$ & $3.6 \pm 0.3$ & $3.6 \pm 0.2$ & $6.6 \pm 0.4$ \\
Apo E & $4.1 \pm 0.3$ & $4.2 \pm 0.2$ & $4.2 \pm 0.2$ & $3.8 \pm 0.2$ \\
\hline
\end{tabular}

Values are expressed in $\mathrm{mg} / \mathrm{dl}$ of mean \pm SEM. 
levels. HDL cholesterol concentrations correlated weakly with whole serum Apo AI ( $\mathrm{r}=$ $0.36, P<0.05)$ and AII $(\mathrm{r}=0.33, P<0.05)$ levels, but no correlation was found between HDL cholesterol levels and whole serum Apo $B$ levels. In contrast, the low molecular weight lipoproteins had significant correlations with Apo AII $(\mathrm{r}=0.37, P<0.05)$ and Apo CII $(\mathrm{r}=$ $0.41, P<0.05$ ), but had no significant correlations with Apo AI, B, CIII or E levels.

\section{DISCUSSION}

In the present study, we first studied cord serum lipoproteins by high performance liquid chromatography. Using the HPLC technique developed by Hara (8), lipoproteins can be separated rapidly with small amounts of serum, and cholesterol can be specifically monitored with an enzymatic reaction of postcolumn effluent. We have demonstrated that cord serum cholesterol separates in three peaks: the first, sharp and the second, broad peaks corresponded to LDL and HDL2 plus HDL3 cholesterol, respectively. The third peak was detected only in cord serum and it appeared in a fraction of lower molecular weight than adult HDL3.

The enzymatic reaction we employed is specific for cholesterol and has little interference (1), indicating that the third peak is formed by cholesterol-containing lipoproteins. Ultracentrifugation methodology, which has been used for isolation of the different HDL subspecies, suffers from extended centrifugation times, resulting in changes in the structure and compositional integrity of the isolated subspecies (15). Although the occurrence of broad HDL in cord serum has been suggested previously using electrophoresis (3), we have demonstrated the presence of lipoprotein particles in the third peak by electron microscopy. These findings indicate strongly the presence of low molecular weight lipoproteins in cord serum.

In order to characterize the small lipoproteins, we investigated the relationship between apoprotein concentrations and the amounts of HDL and the small lipoprotein cholesterol. Apo AI and Apo AII, which are major constituents of adult HDL, had only weak positive correlation with cord serum HDL. In contrast, cord serum HDL correlated significantly with Apo E, CII, and CIII. Apo E is one of the major apoproteins contained in chylomicron and VLDL in adult serum which plays an important role in the transport of lipids via Apo E and Apo B, E receptors (7). Since Innerarity et al. (9) have reported that HDL with Apo E had a stronger binding capacity to Apo B, E receptors than LDL, we speculate that HDL in neonates is rich in Apo E and that HDL may play a role in the transport of cholesterol in a way different from that in adults. On the other hand, $\mathrm{C}$ apoproteins tend to be redistributed among lipoprotein classes. During the absorption of dietary fat and the production of chylomicron or the synthesis of VLDL, $\mathrm{C}$ apoproteins are preferentially distributed on the surface of chylomicron and VLDL. Fasting promotes the association of $\mathrm{C}$ apoproteins with HDL (11). The association of $\mathrm{C}$ apoproteins with HDL in cord serum may result from the similar circumstance that food intake has not been initiated. In contrast to HDL, the amounts of the small lipoproteins in cord serum had a significant correlation with Apo CII and Apo AII, but had no correlation with Apo $\mathrm{E}$ concentrations. These findings may indicate that the composition of apoproteins in the small lipoproteins is different from that of HDL.

The presence of such small lipoprotein particles has been reported in abetalipoproteinemia (4). In neonates, however, it is not likely that HDL is produced from the catabolic products of triglyceride-rich lipoproteins (chylomicron and VLDL), as in abetalipoproteinemia. Subclassification of HDL is demonstrated by ultracentifugation (15) and gradient gel electrophoresis (3). The percentage of HDL3 is three times higher than that of HDL2 in adult serum, while HDL2 and HDL3 are almost equally distributed in cord serum (15). It remains to be elucidated whether the low molecular weight lipoproteins in cord serum belongs to subclasses of HDL or other lipoproteins.

Lipoproteins in cord serum had different properties from those of adult serum: LDL cholesterol was less due to utilization in steroidgenesis (13), and the small lipoprotein particles were present. Characterization of cord serum lipoproteins gives added insight into the dynamic equilibrium of several complex processes in lipoprotein metabolism. 
Received for publication 20 July 1989; and in revised form 23 August 1989

\section{REFERENCES}

1. Allain C. C., Poon L. S., Chan C. S. G., RichMOND W. and Fu P. C. (1974) Enzymatic determination of total serum cholesterol. Clin. Chem. 20, 470-475

2. Bierman E. L., Hayes T. L., Hawkins J. N., Ewing A. M. and Lindgren F. T. (1966) Particle-size distribution of very low density plasma lipoproteins during fat absorption in man. $J$. Lipid Res. 7, 65-72

3. Davis P. A., Forte T. M., Nichols A. V. and BLum C. B. (1983) Umbilical cord blood lipoproteins. Isolation and characterization of high density lipoporteins. Arteriosclerosis 3, 357-365

4. Deckelbaum R. J., Eisenberg S., Oschry Y., Cooper M. and Blum C. (1982) Abnormal high density lipoproteins of abetalipoproteinemia: relevance to normal HDL metabolism. J. Lipid Res. 23, 1274-1282

5. Fordyce M. K., Duncan R., Chao R., Christakis M., Hsia S. L., Robertson E., Kafatos A. and ChristaKIS G, (1983) Cord blood serum in newborns of diabetic mothers. J. Chron. Dis. 36, 263-268

6. Gofman J. W., Jones H. B., Lindgren F. T., Lyon T. P., Elliott H. A. and Strisower B. (1950) Blood lipids and human atherosclerosis. Circulation 2, 161-178

7. Goldstein J. L. and Brown M. S. (1974) Binding and degradation of low density lipoproteins by cultured human fibroblasts. J. Biol. Chem. 249, 5153-5162

8. HARA I. and OKaZAKI M. (1986) High-performance liquid chromatography of serum lipoproteins. Meth. Enzymol. 129, 57-78
9. Innerarity T. L., Bersot T. P., Arnold K. S., Weisgraber K. H., Davis P. A., Forte T. M. and MAHLEY R. W. (1984) Receptor binding activity of high-density lipoproteins containing apoprotein $\mathrm{E}$ from abetalipoproteinemic and normal neonate plasma. Metabolism 33, 186195

10. Lane D. M. and McConathy W. J. (1983) Factors affecting the lipid and apolipoprotein levels of cord sera. Pediatr. Res. 17, 83-91

11. Mahley R. W., Innerarity T. L., Rall S. C. and Weisgraber K. H. (1984) Plasma lipoproteins: apolipoprotein structure and function. $J$. Lipid Res. 25, 1277-1294

12. Noble R. P. (1968) Electrophoretic separation of plasma lipoproteins in agarose gel. J. Lipid Res. 9, 693-700

13. Parker C. R., Carr B. R., Simpson E. R. and MacDonald P. C. (1983) Decline in the concentration of low-density lipoprotein-cholesterol in human fetal plasma near term. Metabolism 32, 919-923

14. Parker C. R., Hankins G. D. V., Carr B. R., Leveno K. J., Gant N. F. and MacDonald P. C. (1984) The effect of hypertension in pregnant women on fetal adrenal function and fetal plasma lipoprotein-cholesterol metabolism. Amer. J. Obstet. Gynecol. 150, 263-269

15. Rosseneu M., Van Biervliet J. P., Bury J. and VINAIMONT N. (1983) Isolation and characterization of lipoprotein profiles in newborns by density gradient ultracentrifugation. Pediat. Res. 17, 788-794

16. Sakai Y., Itakura K., Kanada T., Ebata N., Suga K., Alkawa H., Nakamura K. and Sata T. (1984) Quantitation of apolipoprotein A-I in pooled human serum by single radial immunodiffusion and sodium dodecyl sulfate--Polyacrylamide gel electrophoresis. Anal. Biochem. 137, $1-7$ 